\title{
Complex Partial Seizure as a Presentation of Lemierre's Syndrome
}

\author{
Nayeon Choi, $\mathrm{MD}^{1}$, Yu-jin Jung, $\mathrm{MD}^{2}$ and GilJoon Lee, $\mathrm{MD}^{2}$ \\ ${ }^{1}$ Department of Otorhinolaryngology-Head and Neck Surgery, Samsung Medical Center, Sungkyunkwan University \\ School of Medicine, Seoul; and ${ }^{2}$ Department of Otorhinolaryngology-Head and Neck Surgery, \\ Kyungpook National University School of Medicine, Chilgok Kyungpook National University Hospital, \\ Daegu, Korea
}

\begin{abstract}
- ABSTRACT -
Lemierre's syndrome is difficult to treat with early suspicion because of its various clinical presentations. We demonstrated unusual presentation of Lemierre's syndrome as a complex partial seizure. A 17 year-old female had aggravated symptoms of upper respiratory infection for 2 weeks followed by complex partial seizure during one hour. Laboratory test revealed acute inflammatory state and radiologic images including computed tomography and angiography demonstrated right lateral neck inflammation with internal jugular vein occlusion. She underwent debridement of inflammatory tissue and ligation of internal jugular vein under diagnosis of Lemierre's syndrome. Because of progression of thrombosis of distal internal jugular vein, she had anticoagulation therapy for 3 months. After that, she followed-up without any discomfort. Lemierre's syndrome could be successfully managed by combined surgical and medical treatment. Proper treatment with early suspicion is crucial because it could present various clinical features and cause serious complications. (J Clinical Otolaryngol 2019;30:88-91)
\end{abstract}

KEY WORDS : Lemierre's syndrome $\cdot$ Seizure $\cdot$ Neck $\cdot$ Infection.

\section{Introduction}

Lemierre's syndrome, which is known as postanginal septicemia or human necrobacillosis, is a rare disease of the head and neck that often affects healthy adolescents and young adults. ${ }^{1,2)}$ It has been described as internal jugular vein thrombosis with recent oropharyngeal infection.

Clinical presentation of Lemierre's syndrome was mainly sore throat, neck mass and neck pain. In addition, it could cause several fatal complications such as meningitis, brain abscess, pulmonary thromboem-

논문접수일 : 2018년 12월 26일

논문수정일 : 2019년 4월 22일

심사완료일 : 2019년 5월 29일

교신저자 : 이길준, 41404 대구광역시 북구 호국로 807

경북대학교 의과대학 칠곡경북대학교병원

이비인후-두경부외과학교실

전화 : (053) 200-2166·전송 : (053) 200-2027

E-mail:giljoon.lee@gmail.com bolism with mortality rate of $5 \%$. $^{2)}$

Because of its variety of clinical presentation, early suspicion and treatment of Lemierre's disease has been considered as difficult. In some cases of Lemierrre's syndrome, they revealed neurologic symptoms accompanied by encephalopathy and stroke. ${ }^{2-4)}$ In this report, we demonstrated rare clinical presentation of Lemierre's syndrome as a complex partial seizure.

\section{Case report}

A 17 year-old female was previously healthy and lost body weight about $10 \mathrm{~kg}$ for the purpose of diet during 2 months. Recently, she had cough, sputum and fever for 2 weeks, and symptoms were not relieved in spite of oral antibiotics therapy (amoxicillin/clavulanate). She had complex partial seizure with upper eye ball deviation and loss of consciousness during 1 hour after agitation. 
She was transferred to emergency room of our hospital, and seizure was stopped with antiepileptic drugs. Electoroencephalography was normal and brain magnetic resonance imaging (MRI) revealed no significant focal lesion in the brain parenchyme. However, diffuse inflammatory change adjacent to right internal jugular vein (Fig. 1A) was identified on neck contrast computed tomography (CT) and occluded right internal jugular vein with brain cortical veins enlargement was shown on MR angiography (Fig. 2). On laboratory exam, level of white blood cell (WBC) was $11730 / \mu \mathrm{L}$, C-reactive protein (CRP) was $33.69 \mathrm{mg} / \mathrm{dL}$ and erythrocyte sedimentation rate (ESR) was $120 \mathrm{~mm} / \mathrm{hr}$ on blood test. And there was no abnormal findings on cerebrospinal fluid (CSF).

With the diagnosis of septic thrombophlebitis of right internal jugular vein (Lemierre's syndrome), she underwent radical debridement of necrotic tissue and ligation of right internal jugular vein with intravenous antibiotics administration (piperacillin/tazobactam). The gram stain and culture of surgical specimen was negative. 1 week after the surgery, neck CT demonstrated improved inflammatory change of the right neck, but progression of thrombus was observed at the distal part of the ligated internal jugular vein from level II to level IV (Fig. 1B). Therefore, anticoagulation therapy has been started using intravenous heparin (50 $\mathrm{sec} \leq$ target aPTT $<70 \mathrm{sec}$ ) which was converted to warfarin $(2 \mathrm{sec} \leq$ target $\mathrm{PT}<3 \mathrm{sec})$ in 5 days after the initiation of anticoagulation. After the surgery, antibiotics therapy was performed for 3 weeks until normalization of blood lab (WBC : 6820/ $\mu \mathrm{L}, \mathrm{CRP}: 0.44 \mathrm{mg}$ / $\mathrm{dL}, \mathrm{ESR}: 9 \mathrm{~mm} / \mathrm{hr}$ ) and anticoagulation therapy lasted for 3 months. Three months after surgery, neck CT revealed no inflammation of right neck and no change of internal jugular vein thrombosis (Fig. 1C). She was followed-up until 6 months after the surgery without symptom including fever or seizure.

\section{Discussion}

Lemierre's syndrome is diagnosed in patients who had history of upper respiratory tract infection and radiological evidence of internal jugular vein thrombosis. ${ }^{1,2)}$ Recently, incidence of Lemierre's syndrome has been decreased because of development of antibiotics and diagnostic tools. Otherwise, it demonstrated various clinical presentation such as otalgia, joint pain, and headache, and fatal complication. ${ }^{2,5)}$ Initial presentation of Lemierre's syndrome is mostly tonsillitis followed by pharyngitis and pneumonia. ${ }^{2)}$ In this report, patient presented complex partial seizure with leukocytosis. In this situation, we usually suspect infectious disease of brain such as encephalitis and meningitis, but Lemierre's syndrome could be a final diagnosis. Lemierre's syndrome with seizure or complications of central nervous system (CNS) is rare. Twenty-two cases of CNS complications resulting from Lemierre's syndrome were reported from 1980 to 2010.6 Because CNS complications could result in fatal outcomes including death, we should consider Lemierre's syndrome diagnosing patients who have CNS symptoms. The diagnosis of Lemierre's syndrome is based on clinical suspicion. The computed tomography (CT) scan is the best diagnostic method to evaluate internal jugular vein thrombosis and primary upper respiratory tract infection. ${ }^{6}$ In addition, Doppler ultrasonography could be used to check blood flow and echogenicity of internal jugular vein and adjacent structures. ${ }^{7)}$ Magnetic resonance imaging (MRI) could increase the sensitivity of diagnosis, because it reflect intraluminal signal intensity change by the thrombosis. ${ }^{6}$ We used CT and MRI together to evaluate the disease extent of thrombosis, brain, other soft tissue status.

Surgical drainage and antibiotics therapy has been cornerstone of treatment of Lemierre's syndrome. The first-line antibiotic therapy should involve penicillin/ $\beta$-lactamase inhibitor for $\beta$-lactamase producing pathogens and oropharyngeal oraganisms. ${ }^{2,6)}$ In this case report of culture negative Lemierre's syndrome, piperacillin/tazobactam seemed to be effective medical treatment.

Most of Lemierre's syndrome patients have been managed with surgery and antibiotics, and the effect 

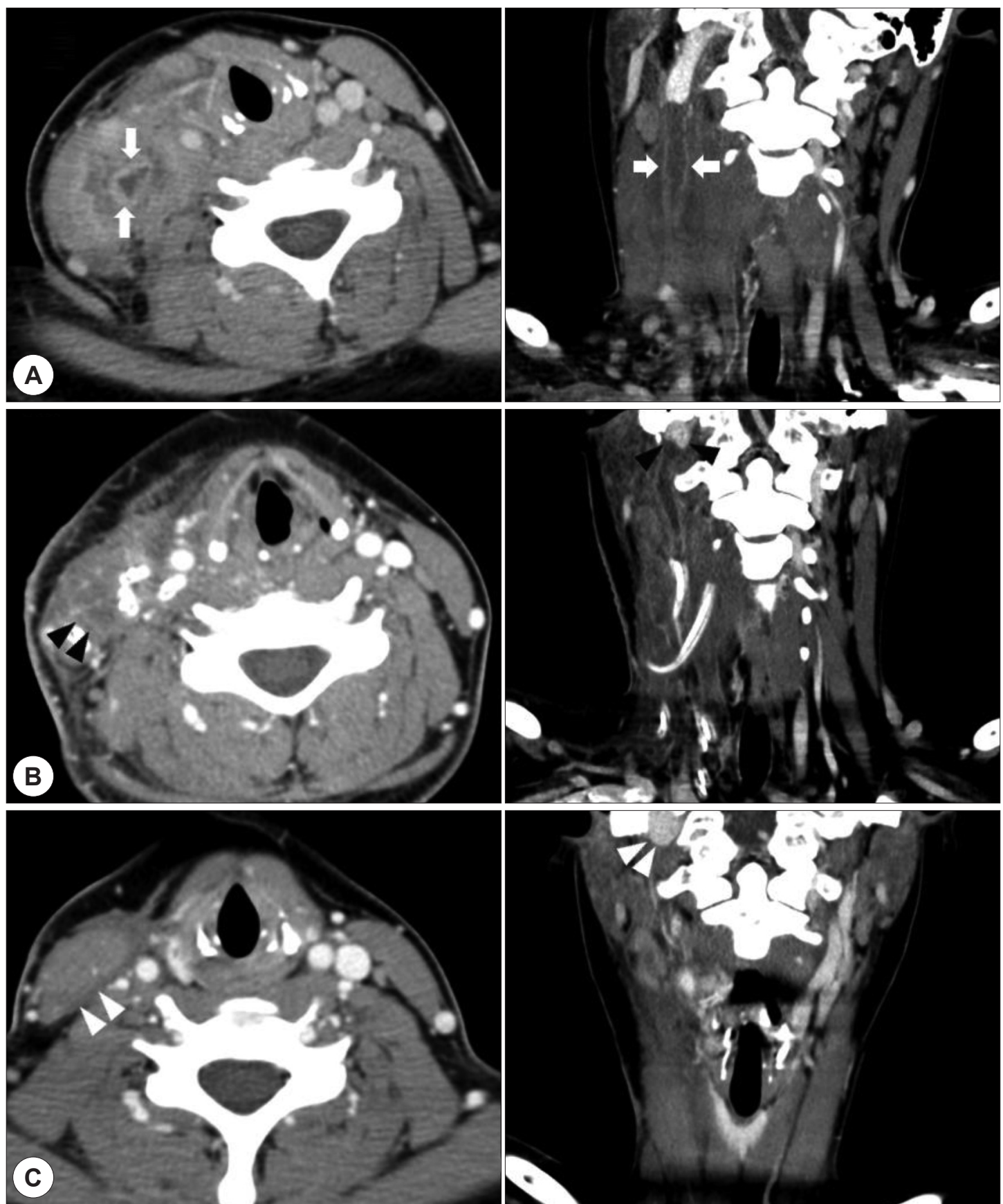

Fig. 1. Serial neck contrast tomography (CT) images of the patient with Lemierre's syndrome. A : Preoperative neck CT showed internal jugular vein (IJV) thrombophlebitis with enhanced adjacent muscles and fluid collection (white arrow). B : 1 week after surgery, neck CT revealed decreased enhancement and fluid collection around lateral neck, but thrombosis of IJV was progress to the skull base side (black arrow head). C : 3 months after surgery, CT imaging demonstrated stable status of IJV thrombosis without inflammatory sign (white arrow head). 


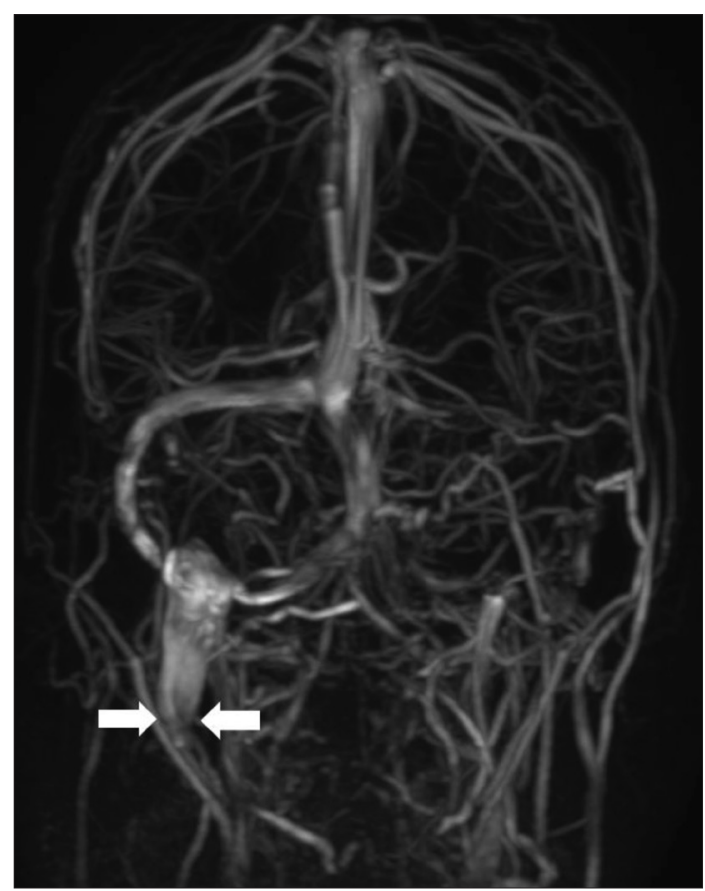

Fig. 2. Preoperative magnetic resonance angiography of brain showed right internal jugular vein obstruction with brain cortical vein enlargement.

of anticoagulant therapy remains controversial. In this case, we treated with anticoagulant because this could result in systemic septic emboli including lung, joint and brain. And we performed serial CT scan after the surgery, and detected improvement of thrombosis progression at distal stump of internal jugular vein. Because the possibility of CNS complications in Lemierre's syndrome, we followed up for 6 months until confirmation of stabilization of thrombosis on radiologic examination.

In summary, Lemierre's syndrome has been decreased but it could make fatal complications. There- fore we should have precise diagnosis with early suspicion, and perform the proper treatment including surgical drainage and antibiotics.

\section{Conclusion}

Lemierre's syndrome could have various clinical presentations, so it is important to treat properly with early suspicion. In this case of Lemierre's syndrome with complex partial seizure, we successfully managed with surgical and medical treatment with antibiotics.

\section{REFERENCES}

1) Lemierre A. On certain septicaemias due to anaerobic organisms. The Lancet 1936;227(5874):701-3.

2) Karkos PD, Asrani S, Karkos CD, Leong SC, Theochari EG, Alexopoulou TD, et al. Lemierre's syndrome: a systematic review. Laryngoscope 2009;119(8):1552-9.

3) Agarwal R, Arunachalam PS, Bosman DA. Lemierre's syndrome: a complication of acute oropharyngitis. J Laryngol Otol 2000;114(7):545-7.

4) Bentham JR, Pollard AJ, Milford CA, Anslow P, Pike MG. Cerebral infarct and meningitis secondary to Lemierre's syndrome. Pediatr Neurol 2004;30(4):281-3.

5) Ridgway JM, Parikh DA, Wright R, Holden P, Armstrong $\mathrm{W}$, Camilon F, et al. Lemierre syndrome: a pediatric case series and review of literature. Am J Otolaryngol 2010;31(1): 38-45.

6) Kuppalli K, Livorsi D, Talati NJ, Osborn M. Lemierre's syndrome due to Fusobacterium necrophorum. Lancet Infect Dis 2012;12(10):808-15.

7) Chirinos JA, Lichtstein DM, Garcia J, Tamariz LJ. The evolution of Lemierre syndrome: report of 2 cases and review of the literature. Medicine 2002;81(6):458-65.

8) Bhatia K, Jones NS. Septic cavernous sinus thrombosis secondary to sinusitis: are anticoagulants indicated? A review of the literature. J Laryngol Otol 2002;116(09):667-76.

9) Bradley DT, Hashisaki GT, Mason JC. Otogenic sigmoid sinus thrombosis: what is the role of anticoagulation? Laryngoscope 2002;112(10):1726-9. 